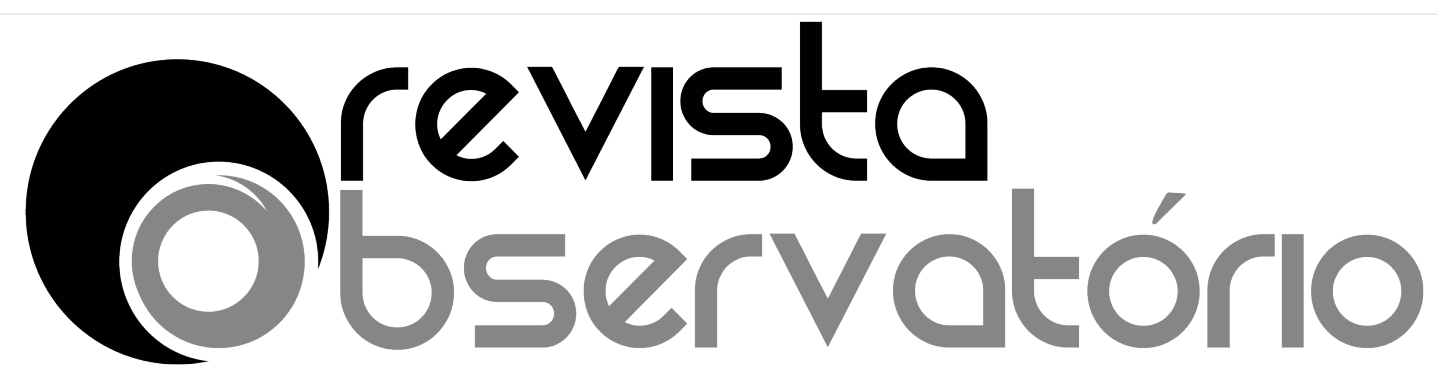

ISSN n² $2447-4266$

Vol. 3, n. 2, Abril-Junho. 2017

DOI: $\underline{\text { http://dx.doi.org/10.20873/uft.2447-4266.2017v3n2p25 }}$

\title{
POR UMA HISTÓRIA PÚBLICA: filigranando Comunicação e Ensino
}

"[...] a história pública pode ser entendida em quatro generosas dimensões, passíveis de entrecruzamentos e interpretações: história para o público, história com o público, história feita pelo público e história e público".

Ricardo Santhiago

A Revista Observatório chega com esperada vivacidade ao seu terceiro ano trazendo com vigor mais um dossiê especial "Por uma História Pública: comunicação e ensino", que reuniu um conjunto de pesquisas que perscrutam temáticas interdisciplinares, mas tendo em comum a ancoragem no amplo espectro da História Pública. Os artigos aqui apresentados interseccionam dimensões da história para o público e da história com o público, no entrelace entre comunicação e ensino. Para além disso, revelam estudos que esquadrinham os usos do passado e no/do presente na perspectiva da História Pública e suas reverberações socioculturais e políticas, a partir de diferentes linguagens como a cinematográfica, iconográfica, literária, museológica e midiática.

Neste contexto, pretende-se contribuir para a ampliação e consolidação das reflexões teórico-práticas em torno da História Pública no Brasil e suas aproximações com as tecnologias digitais, visando a difusão do conhecimento histórico para além da produção 


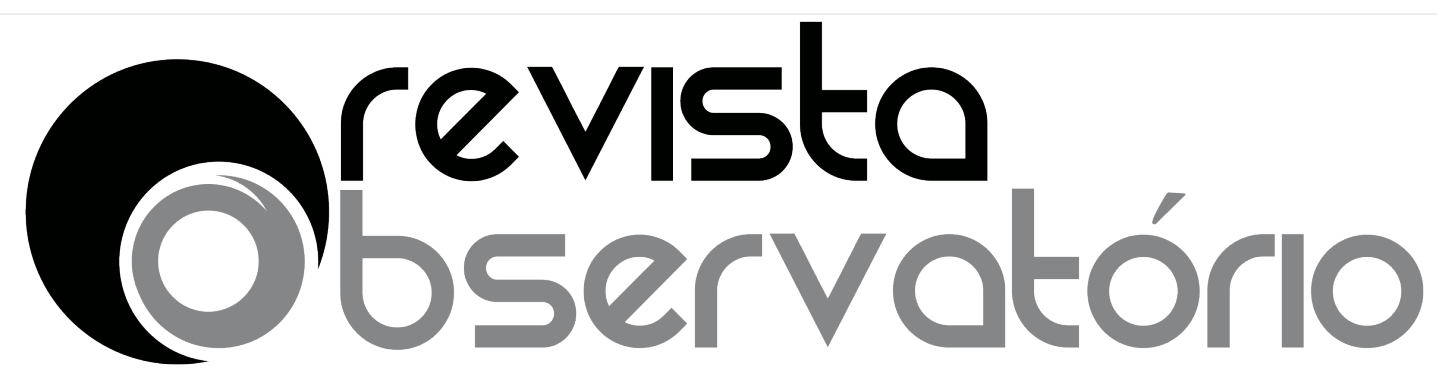

ISSN n² $2447-4266$

Vol. 3, n. 2, Abril-Junho. 2017

DOI: http://dx.doi.org/10.20873/uft.2447-4266.2017v3n2p25

acadêmica, atingindo outros espaços/configurações de produção, divulgação e circulação do saber a outros públicos de ampla audiência. Cabe aos profissionais da contemporaneidade o desafio de filigranar o conceito, o campo, o gerenciamento, os trajetos, os modos, os temas, os problemas e os impactos da História Pública, os desdobramentos na interface entre história e comunicação e suas ubiquidades possíveis na formação da consciência histórica, numa perspectiva transdisciplinar, como é a política editorial desta revista.

Desta forma, a Revista Observatório traz ao público seu segundo número de 2017, com uma temática especial e que conta com o ineditismo, cujo mote figura no panorama que se espraia sob uma miríade caleidoscópica de abordagens teórico-metodológicas e empírico-conceituais, por pesquisadores de diferentes campos e canteiros do saber e de diversas partes do Brasil. Esta edição não deseja ser um mapeamento, mas porta o intento de representar um microcosmo da diversidade temática, intentando dar mostras da atual polifonia sobre História Pública, ao apresentar-lhes um consórcio de contribuições com a diversidade institucional de autores e de membros nacionais e internacionais dos conselhos editorial e consultivo, são metas constantemente perseguidas, por nossa política editorial. Mantemo-nos firmes ao propósito inicial e eixo de análise, arquiteturado por este periódico desde sua gênese primando qualidade e exogenia. O periódico é vinculado ao Núcleo de Pesquisa e Extensão Observatório de Pesquisas Aplicadas ao Jornalismo e ao Ensino (OPAJE), da Universidade Federal do Tocantins (UFT) em parceria com o Grupo de Pesquisa em Democracia e Gestão Social (GEDGS), da Universidade Estadual Paulista "Júlio de Mesquita Filho" (UNESP), continua a fomentar, promover e viabilizar o debate acadêmico de estudos trans/multidisciplinares no campo da Comunicação, do Jornalismo e da Educação. 


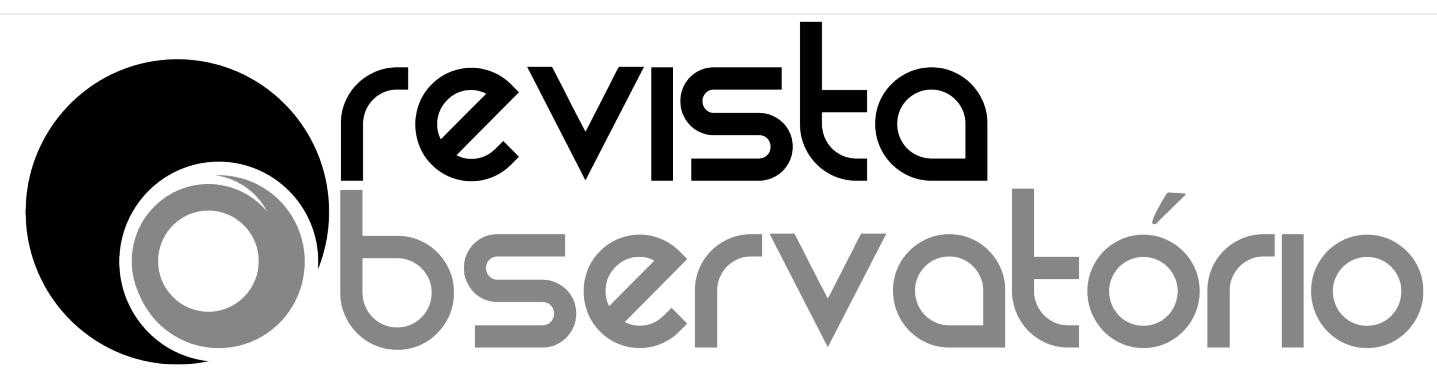

ISSN n² $2447-4266$

Vol. 3, n. 2, Abril-Junho. 2017

DOI: http://dx.doi.org/10.20873/uft.2447-4266.2017v3n2p25

Entre os dados construídos, ao longo destes quase três anos podemos elencar, o periódico tem aumentado consideravelmente o fluxo de submissões de manuscritos cujos vínculos institucionais dos autores estão cada vez mais diversos, submetidos ao escrutínio dos membros do Conselho Editorial Nacional e Internacional e de parceiristas ad hoc. Temos empreendido esforços conjuntos para reduzir o tempo médio entre a submissão, aceitação ou não e a publicação, sem perder de vista os índices de endogenia e exogenia. Outrossim, temos realizado atualizações e constantes indexações nacionais e internacionais para atender as emergentes políticas editoriais do sistema de publicações científicas no Brasil, com vistas a adensar o debate qualificado e atingir as diretrizes de qualidade nos artigos. Destarte, temos realizado ações que visem para os próximos semestres captar recursos por veio das agências de fomento para realização e revisões orto-gramaticais e semânticas profissionais, sobretudo, para pensarmos em publicações bilíngues no futuro próximo, como está que realizamos na entrevista nas versões em português, francês e espanhol.

Destarte, a cada edição que lançamos, tomamos como um exercício de autoavaliação, que nos possibilita replanejarmos na direção do aprimoramento de nosso periódico, para assim integrarmos o seleto conjunto dos periódicos brasileiros de elevada qualidade. Diante disto, é preciso sublinhar que temos, nos últimos meses, realizado ações para imprimir mais agilidade ao processo editorial, bem como, dado importantes passos no sentido da internacionalização do periódico, o que tem nos demandado hercúleos esforços na construção de parcerias às próximas edições, sentido este, em que a revista vai ao encontro ao conjunto de determinações formuladas pelo conjunto dos avaliadores internacionais. O projeto que desejamos ver cumprido pressupõe maior afunilamento do 


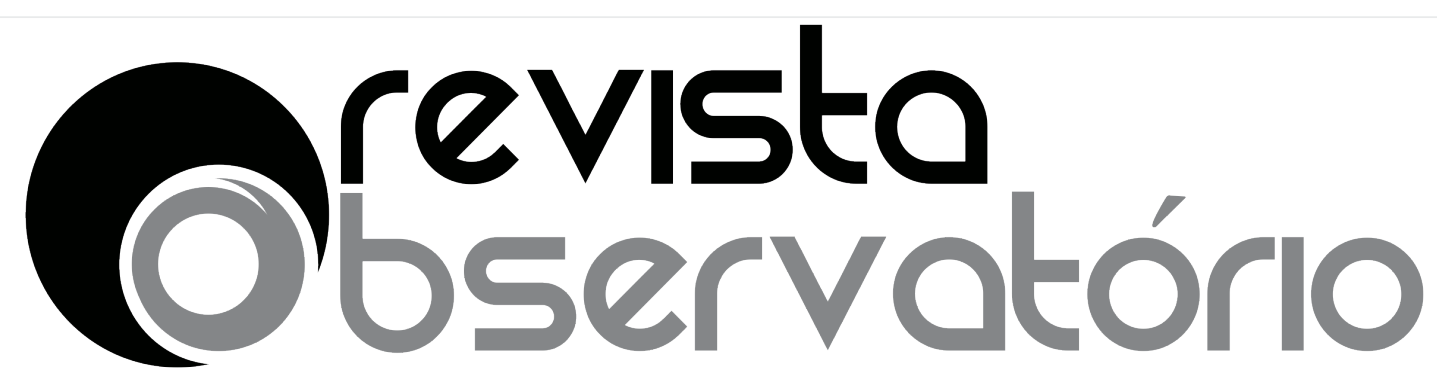

ISSN n² $2447-4266$

Vol. 3, n. 2, Abril-Junho. 2017

DOI: http://dx.doi.org/10.20873/uft.2447-4266.2017v3n2p25

crivo avaliativo, visto que tem aumentado o número de submissões, exigindo dos avaliadores, maior perícia no processo.

Com este intento, apresenta-se o artigo que inaugura o dossiê, HISTÓRIA PÚBLICA: a comunicação e a educação histórica, assinado por Marta Gouveia de Oliveira Rovai. A autora tem como proposta apresentar o conceito e as práticas de História Pública como um novo posicionamento da ciência histórica em diálogo com profissionais da comunicação, no sentido de produzir e divulgar as experiências humanas. Para isso, discute-se a origem do conceito de História Pública e as diferentes formas de educação histórica que a utilização das novas tecnologias podem proporcionar (dentre elas a internet). Nesse sentido, convida-se o leitor para a reflexão sobre as possibilidades de publicização e de democratização do conhecimento histórico e da cultura, ampliando-se a oportunidade de produção, de divulgação e de acesso do público a diferentes formas experiências no tempo.

HISTÓRIA PÚBLICA E EDUCAÇÃO DEMOCRÁTICA: professores contra o Projeto Escola Sem Partido, de autoria de Juniele Rabêlo de Almeida e Renan Rubim Caldas, centra como ponto de atenção a interface entre a História Pública e a Educação, para além dos espaços formais de educação, analisando as práticas e resistências dos professores na defesa de uma educação plural e visando o fortalecimento do debate público, por meiodo movimento Professores Contra o Escola Sem Partido. Contra a acusação da existência da "doutrinação ideológica" nas escolas apontadas pelo Programa Escola Sem Partido, defende-se com veemência a liberdade e autonomia docente e uma História Pública cada vez mais plural e democrática.

O terceiro artigo, HISTÓRIA ESCOLAR, CINEMA BRASILEIRO E HISTÓRIA PÚBLICA: caminhos de uma memória, escrito por Vitoria Azevedo da Fonseca, promove uma reflexão a 


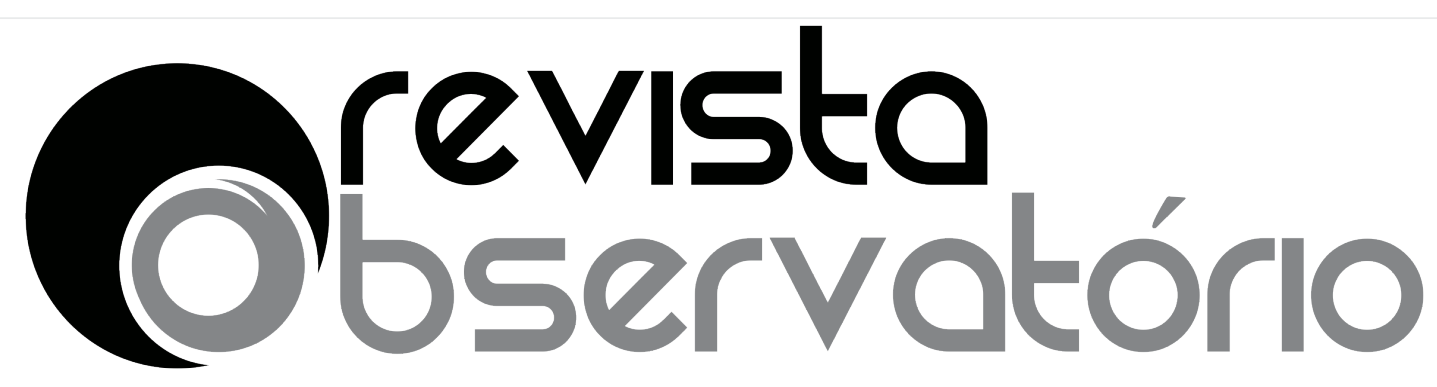

ISSN n² $2447-4266$

Vol. 3, n. 2, Abril-Junho. 2017

DOI: http://dx.doi.org/10.20873/uft.2447-4266.2017v3n2p25

respeito dos usos de temáticas históricas nas produções cinematográficas brasileiras. A autora aponta que nos últimos 20 anos houve a produção de 240 filmes do cinema brasileiro com temática histórica, numa perspectiva da história escolar para um grande público, entre ficções e documentários. O texto chama atenção para as temáticas mais recorrentes, desde biografias, ditadura militar, escravidão, Era Vargas, até a questão indígena, mostrando como o cinema é um instrumento de publicização da história ao qual devemos prestar maior atenção.

O estudo de Joseli Mendonça Maria Nunes Mendonça e Renê Wagner Ramos AFROBRASILEIROS NO MUSEU PARANAENSE: silêncios, demandas públicas e resignificações, perscruta a relação do público com o passado e os constructos narrativos que se inserem no campo da História Pública, interfaciando as práticas museológicas aplicadas ao ensino de História e as formas de representações da população afro-brasileira, feitas pelo Museu Paranaense em Curitiba/PR. O artigo aponta para práticas de valorização da história social e econômica no processo de migração europeia na região, chamando a atenção - ao mesmo tempo - para a invisibilização do papel do negro na formação e no processo de construção da sociedade paranaense. Apresentam-se questionamentos sobre as abordagens restritas aos elementos da prática escravocrata, ignorando o protagonismo histórico que as populações negras tiveram na história do Paraná. Dos silenciamentos e dos desafios históricos e museais, a pesquisadora destrinça a museografia do Museu Paranaense.

O texto HISTÓRIA PÚBLICA E ENSINO DE HISTÓRIA: um olhar sobre o filme no livro didático, de Rodrigo de Almeida Ferreira, traz um candente debate acerca dos diálogos possíveis entre o ensino de História e a História Pública, tomando como eixo central a fina análise de duas produções fílmicas com temática histórica: Xica da Silva e Chico Rei. 


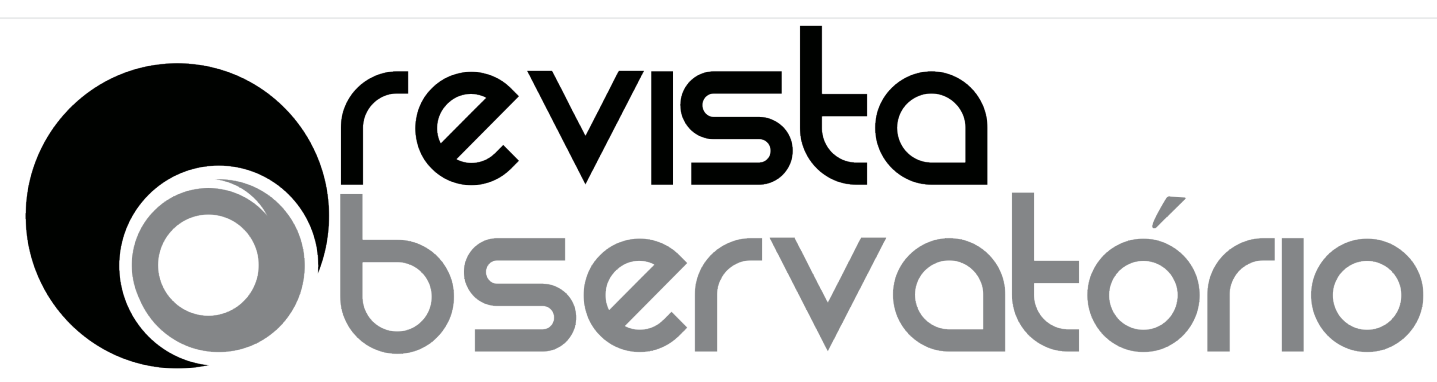

ISSN n² $2447-4266$

Vol. 3, n. 2, Abril-Junho. 2017

DOI: http://dx.doi.org/10.20873/uft.2447-4266.2017v3n2p25

Demonstrando como estes filmes são tratados pelos livros didáticos de História, entre 19782006, o autor promove uma reflexão sobre as relações entre a abordagem do cinema e o uso dos livros didáticos na construção de uma História Pública, ressignificando o conhecimento e o ensino de História voltado ao grande público. O artigo contribui para pensarmos como a história pode ser publicizada e popularizada sem ser simplista.

As historiadoras Maria de Fátima de Morais e Sônia Maria de Meneses Silva, no texto "NO SILÊNCIO OBSEQUIOSO, PREPARO MINHA PRÓPRIA DEFESA": Padre Cícero, arquivista de si mesmo, lança luz sobre as práticas arquivísticas do padre Cícero Romão Baptista. A pesquisadora fez um levantamento da farta documentação deixada pelo Padre Cícero ao longo de sua trajetória religiosa e política, quando ele se preocupava em copiar e guardar documentos escritos e iconográficos, de modo a construir um acervo documental sobre si mesmo. O que se costuma chamar de "grande arquivo do padre Cícero" é composto por cartas, telegramas, fotografias, artigos de jornais, dentre outros, que hoje está sendo divulgado para se promover o debate em torno do próprio mito nordestino. Trata-se de um exemplo de construção de "um arquivo de si" que, de modo silencioso, mas intencional, preparava sua defesa para o futuro e buscava uma representação de si, a partir da seleção de documentos sobre sua vida, nas primeiras décadas da chamada República Velha nordestina.

A HISTÓRIA PÚBLICA E A CONSTRUÇÃO DO "POPULAR" NO ACERVO DE CORDÉIS DA FUNDAÇÃO CASA DE RUI BARBOSA (1961-2012), por Antonio Helonis Borges Brandão, nos brinda com um debate que toma a literatura de cordel enquanto processo de construção histórica. Neste sentido, sua oficina historiográfica tem sido a Fundação Casa de Rui Barbosa, guardiã de um grande acervo de literatura de cordel no Brasil, modificando o olhar sobre o que se valorizar e o que se divulgar sobre a história. A cultura popular aqui ganha destaque, 


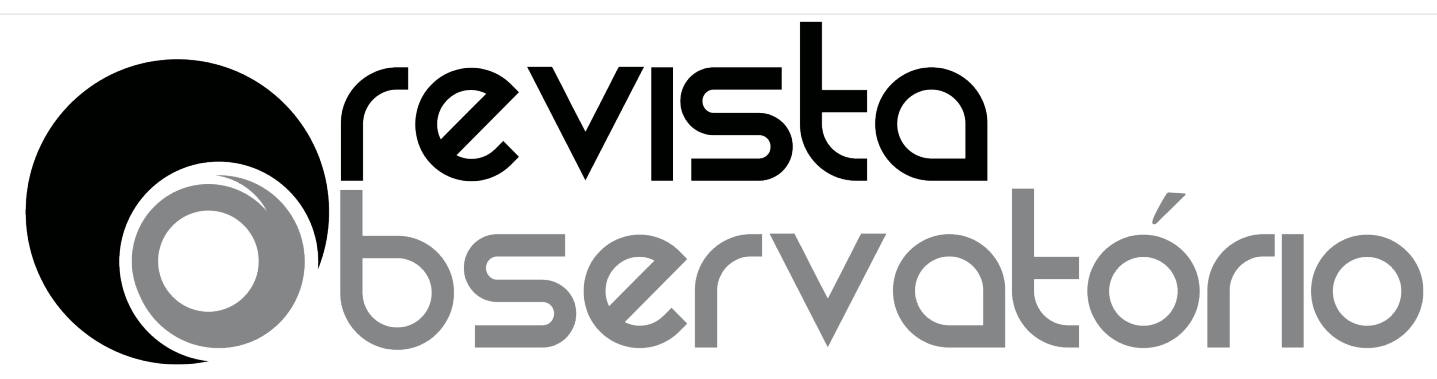

ISSN n² $2447-4266$

Vol. 3, n. 2, Abril-Junho. 2017

DOI: http://dx.doi.org/10.20873/uft.2447-4266.2017v3n2p25

demonstrando-se os caminhos entre a produção, a circulação e o consumo da literatura de cordel, a partir de uma interpretação e de apropriação múltipla e mais ampla, o que se apresenta como rico objeto de estudo para o historiador preocupado com a democratização da história.

A pesquisadora Fabiana Bruce Silva em SOBRE AS PERGUNTAS QUE PODEMOS FAZER AOS ARQUIVOS VISUAIS: por uma história pública, comunicação e ensino, trata de como experiências anteriores com arquivos e coleções fotográficas datadas de meados do século $\mathrm{XX}$, levaram-na a pensar sobre as imagens que os sujeitos, as instituições e as épocas compartilham em vivências cotidianas. As fotografias podem ser acessadas não somente em acervos, também na internet, em exposições, no cinema, na sala de aula e em outros espaços de convivência, sob a perspectiva da História Pública. A autora analisa o acervo fotográfico de Benício Dias, representando o Recife e as formas como a fotografia pode colaborar para a difusão e a construção de memórias, reconstituindo percursos e compreendendo ecos das vivências históricas que aparecem visualmente como escolhas e monumentos.

O artigo DITADURA CIVIL MILITAR NO BRASIL E O ENSINO DE HISTÓRIA: leituras variadas e diferentes maneiras de expressão, das historiadoras Telma Bessa Sales e Viviane Prado Bezerra, problematiza um dos mais importantes períodos da história do Brasil República, a ditadura civil-militar, traçando paralelos possíveis entre os fatos atuais da história política do Brasil e considerando a conjuntura parlamentar e jurídico-midiático ocorrido em 2016. Destarte, o autor analisa o documentário Eu quero ver, enquanto produção fílmica que aborda a história imediata e opera como instrumento de reflexão e publicização de conteúdo histórico, no esteio da História Pública, articulando as entrevistas 


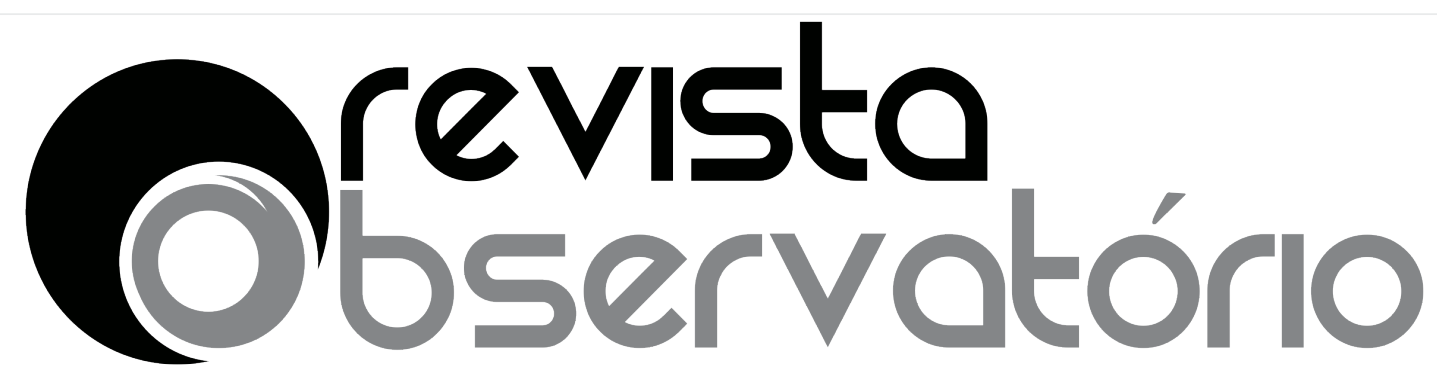

ISSN n² $2447-4266$

Vol. 3, n. 2, Abril-Junho. 2017

DOI: http://dx.doi.org/10.20873/uft.2447-4266.2017v3n2p25

de jovens professores de história da rede pública às narrativas de experientes professores que vivenciaram a ditadura militar brasileira.

Noutros termos, o artigo PENSANDO A ESCRITA DE SI COMO FONTE DE CONHECIMENTO HISTÓRICO, de Simone Pereira da Silva, trata da escrita de caráter biográfico, produzida por Yony Sampaio sobre a família Sá Barreto, considerada uma das mais importantes econômica e politicamente da cidade de Barbalha, localizada no Cariri, no Ceará. A preocupação é demonstrar como a produção e a difusão de uma biografia é uma forma de se fazer uso político do passado. O controle de arquivos e a seleção de documentos e lembranças podem contribuir para a manutenção de relações de poder e o controle, no futuro, das memórias que as novas gerações devem ter sobre o passado. Isso significa pensar num tipo de história voltada para o público e não com ele, demonstrando que a história pública pode se converter num processo de privilégios e não, necessariamente, de democratização da história.

O texto EM CARTAZ: festivais de cinema de arquivo - preservação e público, produzido por Juliana Muylaert Mager e Ana Maria Mauad, demonstra como nas últimas décadas se constituiu o Festival Internacional de Cinema de Arquivo, evento que foi substituído pelo Arquivo em Cartaz em 2015. Segundo a autora, o fenômeno dos festivais se relaciona com o tratamento do patrimônio audiovisual ao longo do século $X X$ e $X X I$, sendo inseparável da trajetória das instituições arquivísticas. $\mathrm{O}$ artigo analisa dois festivais de cinema de arquivo e de cinema e patrimônio como parte desse processo de disputa para a implementação de políticas públicas de preservação do patrimônio audiovisual. A História Pública apresenta-se, assim, como parte de um trabalho realizado não apenas por historiadores, mas também por 


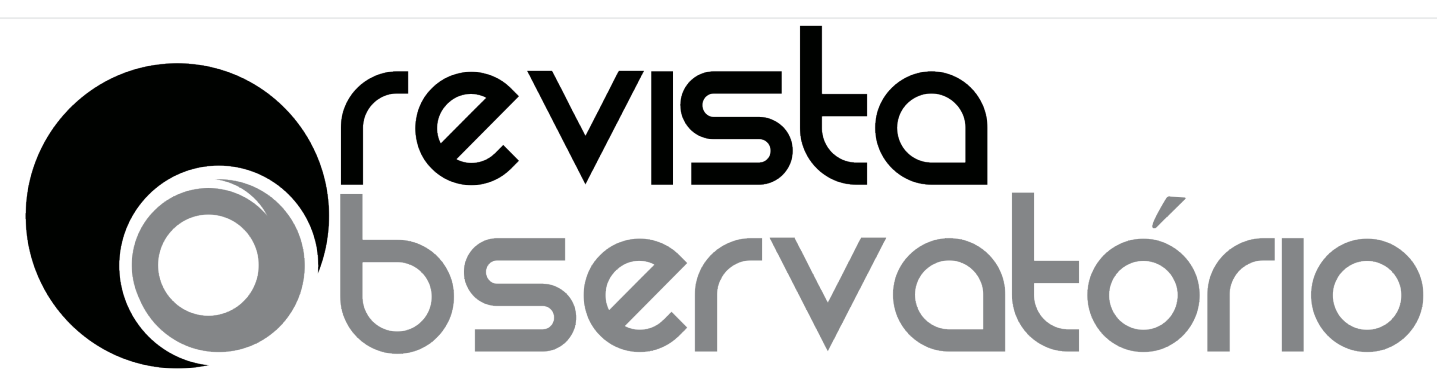

ISSN n² $2447-4266$

Vol. 3, n. 2, Abril-Junho. 2017

DOI: http://dx.doi.org/10.20873/uft.2447-4266.2017v3n2p25

especialistas preocupados com outros tipos de relação com os usos do passado, por meio da história e da comunicação, de acordo com as suas necessidades e desejos de seu tempo.

Já em O ENSINO DE HISTÓRIA E UM TEXTO EM CONTEXTOS: uma leitura sobre o livro História da Liberdade no Brasil, de Viriato Corrêa, Cristiano Gomes Lopes, Vasni de Almeida e Dhiogo Rezende Gomes analisam o livro de Viriato Corrêa, passando por diferentes contextos históricos, a fim de compreender como o conceito de liberdade ganha diversos sentidos, dependendo das intencionalidades de seus usos: o seu lançamento em 1962, seu uso como tema de enredo de samba pela Escola de Samba Salgueiro, no carnaval de 1967, e o momento de sua $2^{a}$ coedição pelo Instituto Nacional do Livro (INL) em 1974. A difusão e a circulação do livro, em temporalidades diversas demonstram o quanto a ideia de "luta por liberdade no Brasil", ganha novos sentidos, servindo aos interesses de conservação da ordem política ou da resistência popular aos ditames ditatoriais.

A seção do dossiê é encerrada pelo artigo A PRÁTICA EXTENSIONISTA E EDUCAÇÃO PATRIMONIAL: esforços em prol de uma história pública. Cícera Patrícia Alcântara Bezerra, Jucieldo Ferreira Alexandre e Priscilla Régis Cunha de Queiroz tratam de como as ações extensionistas universitárias, muitas vezes esquecidas ou desvalorizadas na Universidade, podem contribuir para a construção coletiva e plural do conhecimento histórico, dialogando com as proposições da História Pública. Apresentam as práticas do curso de Bacharelado em História, na Universidade Federal do Cariri, sediado em Icó/CE, junto à comunidade local, envolvendo estudos e ações de educação patrimonial. Com o envolvimento da comunidade, a ideia de História Pública transforma-se num trabalho coletivo de valorização dos bens locais, procurando atender às demandas dos habitantes de Icó, ao mesmo tempo em que sensibiliza discentes para o compromisso com a História Pública. 


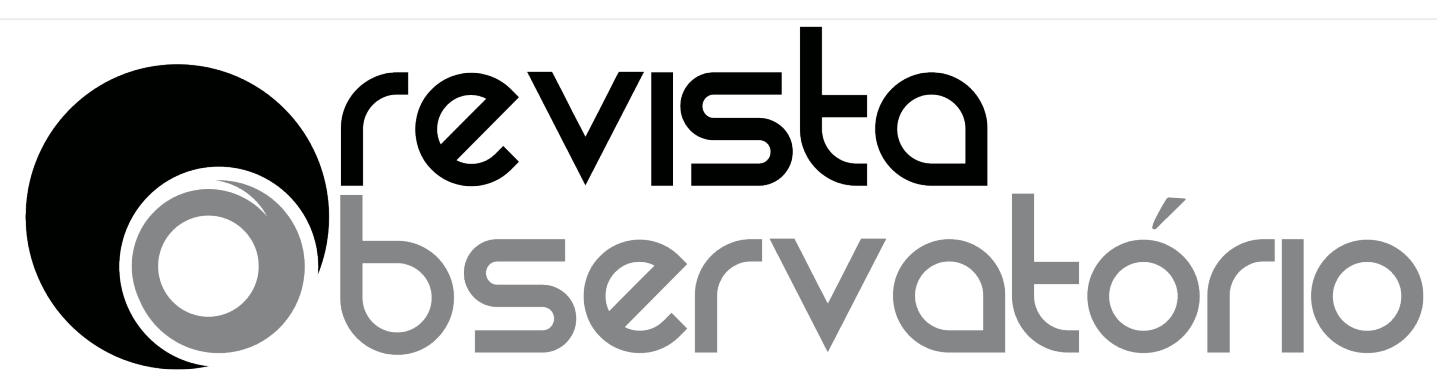

ISSN n² $2447-4266$

Vol. 3, n. 2, Abril-Junho. 2017

DOI: http://dx.doi.org/10.20873/uft.2447-4266.2017v3n2p25

Na seção de Artigos Livres, apresentamos a produção de Lucia Santa Cruz, 50 ANOS DE JORNALISMO DA GLOBO: recordar para reafirmar. O texto analisa a série especial 50 anos de jornalismo da Globo, exibida em cinco episódios ao final do Jornal Nacional, na semana do aniversário de meio século da emissora, em abril de 2015. Com a participação de 16 jornalistas, que relembram momentos marcantes do jornalismo, o Programa é considerado aqui como uma "memória enquadrada", evocando a importância do telejornalismo e valorizando a qualidade do trabalho desenvolvido pela emissora, numa tentativa de se combater a imagem de queda na popularidade da própria emissora.

"E OS CABOCLOS FORAM SE ACABANDO": A (re)construção de sentidos do passado dos Caboclos da Vila de Guarany, Marcos Felipe Vicente se debruça sobre a grande contribuição da história oral como fundamento teórico-metodológico, para a valorização e publicização da memória dos descendentes dos Caboclos de Guarany, no início do século $X X I$, e a representação de seu passado ancestral, na luta pelo direito à terra. A seleção de memórias é uma forma de atribuir sentido ao passado e ao presente, questionando outras versões que representam a exclusão social. No caso, os descendentes de caboclos Gurarany demonstram, por meio de suas narrativas, uma constante resistência ao processo de expropriação e, principalmente, ao esquecimento produzido pela sociedade sobre os conflitos e violação de direitos.

Noutro sentido, o texto PEQUIÁ DA CONQUISTA: a vitória dos de baixo contra os gigantes do Ferro, assinado por Francisco das Chagas Sousa, Eduardo Vacovski e Fagno da Silva Soares, analisa o processo histórico de mobilização social de 312 famílias do bairro Pequiá de Baixo, em Açailândia/MA, impactadas pelo Projeto Grande Carajás desde meados dos anos de 1980, quando fora transformado à revelia de seus moradores, em Distrito 


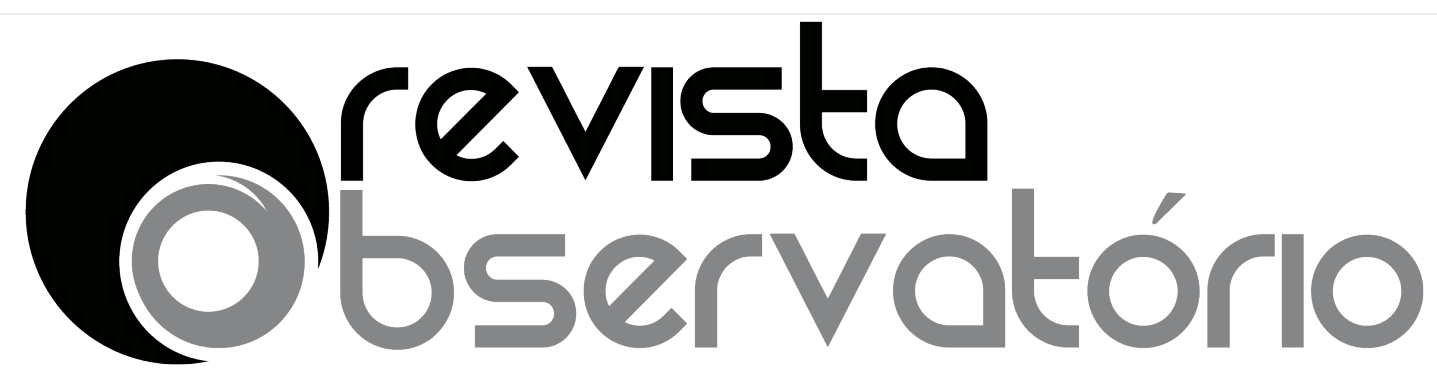

ISSN n² $2447-4266$

Vol. 3, n. 2, Abril-Junho. 2017

DOI: http://dx.doi.org/10.20873/uft.2447-4266.2017v3n2p25

Industrial, com a instalação da mineradora Vale e de cinco empresas siderúrgicas, as quais os autores chamam de os Gigantes do Ferro. Os pesquisadores descrevem o cenário e as práticas de resistências empreendidas pelas famílias afetadas e sua mobilização social que resultaram no processo de reassentamento, ainda em curso das famílias para um novo bairro, que por eleição de seus futuros moradores se chamará Pequiá da Conquista, fazendo alusão ao resultado de uma luta travada durante três décadas pela comunidade contra o grande capital.

No texto EXPERIÊNCIAS DOS MILITANTES DE ESQUERDA ARMADA NOS CÁRCERES CEARENSES (1971-79), o pesquisador José Airton apresenta-nos as experiências cotidianas e relações entre os militantes de esquerda armada no Ceará, no período ditatorial. Aborda o modo como estes contribuíram, a partir da solidariedade e do apoio mútuo na conformatação das relações e articulações entre os presos políticos, para a reconstrução identitária e de luta após a derrota da luta armada que resultou na condenação e encarceramento no Instituto Penal Paulo Sarasate, nos anos 1970. Sob intermitente vigilância da ditadura militar, tidos como 'terroristas', os militantes de esquerda tiveram de buscar táticas (para utilizar termos de Michel de Certeau), na luta pela sobrevivência na vida no cárcere, como a greve de fome de 1974.

No texto PINTURA Y EDUCACIÓN O EDUCACIÓN Y PINTURA: Una propuesta desde la didáctica, Víctor Manuel Amar Rodríguez se debruça sobre um diálogo, possível e existente, entre a pintura e a didática. $O$ foco do autor analisar a intervenção da ação didática, que pensa, sente e atua sobre e para o alunado. Analisa também uma possível valoração com foco na avaliação, no nível particular através dum diário pessoal e participação em um blog. 


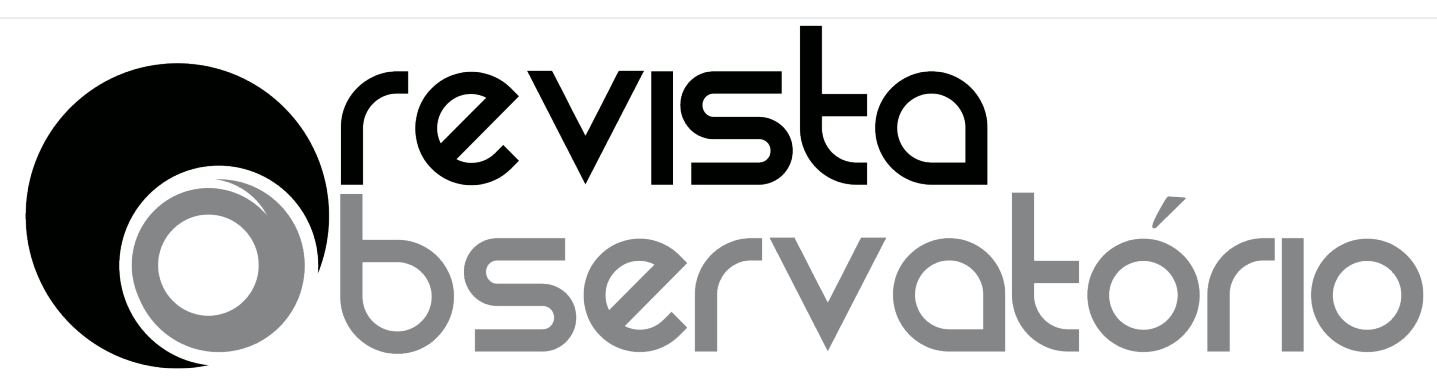

ISSN n² 2447-4266

Vol. 3, n. 2, Abril-Junho. 2017

DOI: http://dx.doi.org/10.20873/uft.2447-4266.2017v3n2p25

Já em A TELEVISION ADVERTISING AND CHILD OBESITY: Characteristics and literature review regarding the Brazilian context, Helder de Melo Moraes, Cristina Galamba Marreiro e Eneus Trindade Barreto Filho discutem a obesidade infantil sob o foco dos pesquisadores brasileiros de publicidade. O estudo propõe o aprofundamento da discussão da relação da publicidade, veiculada na televisão, com a obesidade infantil, no contexto brasileiro, utilizando a plataforma CAPES como fonte principal para a pesquisa.

Wolfgang Teske e Marina Haizenreder Ertzogue em IDENTIDADE CULTURAL E INCLUSÃO TECNOLÓGICA EM UMA PERSPECTIVA FOLKCOMUNICACIONAL DA COMUNIDADE QUILOMBOLA LAGOA DA PEDRA, ARRAIAS-TO, discutem como se operam os intercâmbios folkcomunicacionais na Comunidade Quilombola Lagoa da Pedra, Arraias, Tocantins, e suas práticas de resistência cultural, em um século caracterizado como sendo uma sociedade da informação. Por este motivo, é feita uma abordagem sobre a atual conjuntura econômica mundial e globalização, bem como a inclusão tecnológica, com a utilização das novas tecnologias de comunicação e informação, em uma comunidade quilombola.

Por fim, no texto A UTILIZAÇÃO DO PLANEJAMENTO ESTRATÉGICO SITUACIONAL NA GESTÃO DA PRÓ-REITORIA DE EXTENSÃO E CULTURA (PROEX) DA UNIVERSIDADE FEDERAL DO TOCANTINS (UFT), Waldecy Rodrigues, Tássia Reury Mesquita, Elainy Silva Coelho e Airton Cançado discutem uma metodologia de planejamento estratégico, o Planejamento Estratégico Situacional (PES), tendo por referência a utilização desta em um caso concreto - a gestão da Pró-Reitoria de Extensão e Cultura da Universidade Federal do Tocantins (UFT).

Para finalizar, na seção Entrevistas trazemos, nas versões português, francês e espanhol, a temática A HISTÓRIA PÚBLICA NO BRASIL ENTRE PRÁTICAS E REFLEXÕES: a 


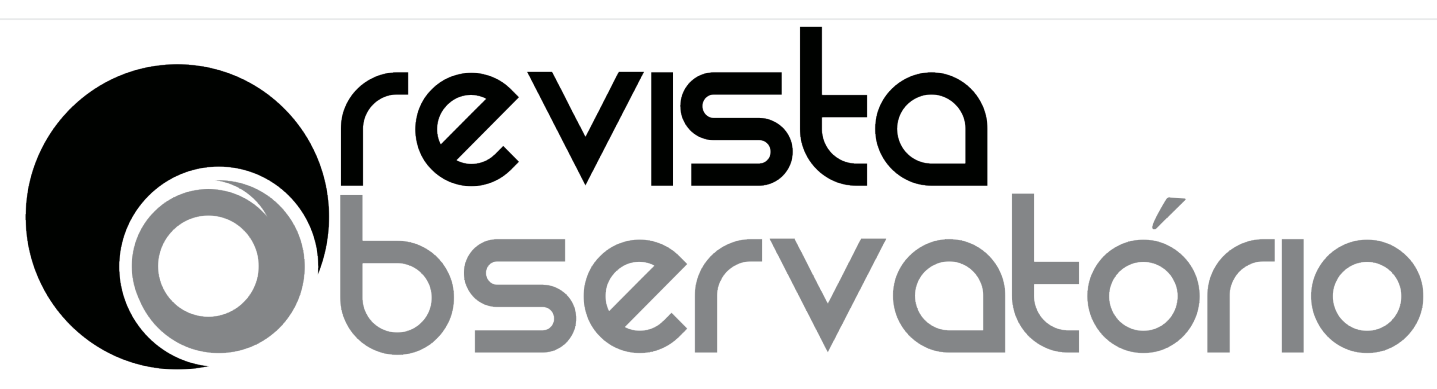

ISSN n² $2447-4266$

Vol. 3, n. 2, Abril-Junho. 2017

DOI: http://dx.doi.org/10.20873/uft.2447-4266.2017v3n2p25

oficina historiográfica, num diálogo de Fagno da Silva Soares com Ricardo Santhiago, pesquisador de pujante produção historiográfica, acerca dos aspectos teórico-metodológicos da História Oral e da História Pública no Brasil. Santhiago é também fundador e membro da coordenação da Rede Brasileira de História Pública [RBHP] no Brasil, professor da Universidade Estadual de Campinas [UNICAMP], associado à Oral History Association [OHA, USA]; à Associação Brasileira de História Oral [ABHO] e ao National Council on Public History [NCPH, USA]. O entrevistado trata de sua trajetória profissional, enquanto comunicólogo e historiador, e faz diversas reflexões sobre a conceituação, trajetória e ampliação das experiências e conceitos que envolvem a História Pública brasileira, além de seu contributo, como intelectual, neste processo de construção e ampliação teórico-metodológica.

Na seção Resenha, trazemos duas contribuições, sendo a primeira, ARGUMENTOS POR UMA HISTÓRIA PÚBLICA: perspectivas e possibilidades, assinada por Ivaneide Barbosa Ulisses. Trata-se de uma coletânea pioneira no Brasil, com título Introdução à História Pública organizada pelas historiadoras Juniele Rabêlo Almeida e Marta Gouveia de Oliveira Rovai e publicada pela editora Letra e Voz, em 2011. A publicação desta obra, certamente abriu caminhos para a realização do "10 Simpósio Internacional de História Pública: $A$ história e seus públicos", realizado na Universidade de São Paulo (USP, 2012), do "20 Simpósio Internacional de História Pública: Perspectivas da História Pública no Brasil", na Universidade Federal Fluminense (UFF, 2014) e do "30 Simpósio Internacional de História Pública: História pública em debate", na Universidade Regional do Cariri (URCA, 2016).

A resenha HISTÓRIA PÚBLICA NO BRASIL: entre interdisciplinaridade e singularidades dos saberes por Samira Moratti Frazão, da obra História Pública no Brasil: Sentidos e itinerários, lançada em 2016 pela editora Letra e Voz, sob a organização dos historiadores 


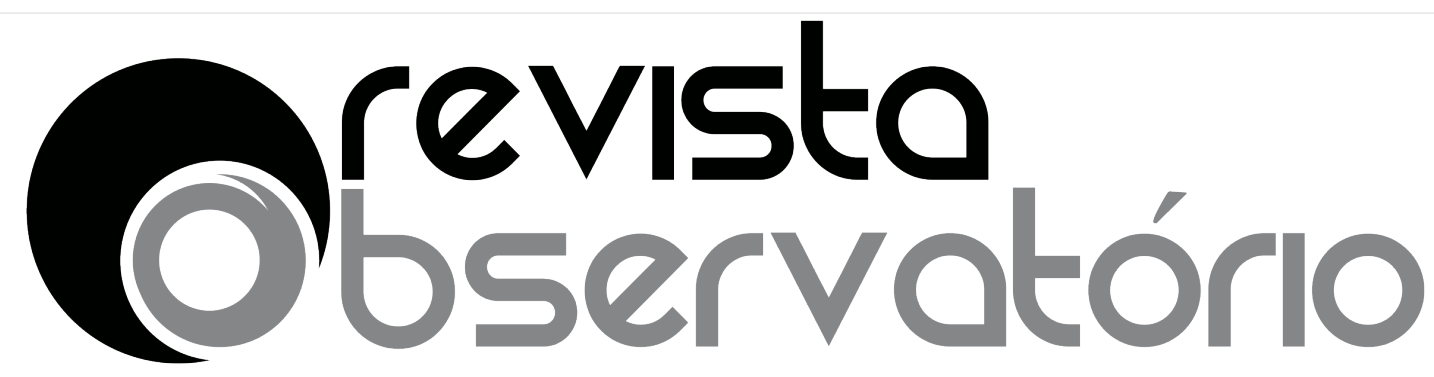

ISSN n² 2447-4266

Vol. 3, n. 2, Abril-Junho. 2017

DOI: http://dx.doi.org/10.20873/uft.2447-4266.2017v3n2p25

Ana Maria Mauad, Juniele Rabêlo de Almeida e Ricardo Santhiago. Trata-se de uma obra inaugural com um conjunto de ensaios que trazem elementos teórico-metodológicos sobre as práticas da Public History no Brasil. Sob a rubrica da Rede Brasileira de História Pública (RBHP, 2012), a obra contém subsídios para pensar a atual polifonia deste métier, dando a ver os debates novelados desta história feita para, com e pelo público, fruto de um conjunto de reflexões apresentada durante os primeiros simpósios internacionais da área realizados no Brasil.

A partir de tamanha diversidade, sejam todos bem-vindos à reflexão coletiva e ao compromisso "Por uma História Pública: comunicação e ensino", pensando sobre a história para o público, com o público, pelo público e a história e o público. Desejamos que as provocações, questionamentos, experiências e sugestões aqui apresentados sejam como flechas de muitas aljavas, que encontrem ressonâncias e possam grassar para além dos cursos de Comunicação Social, Educação, Ciências da Informação, História e áreas correlatas. Este dossiê a isto se propõe.

Saudações alvissareiras. Estimadamente Evoé!

Rio de Janeiro/RJ, São Paulo/SP, Palmas-TO, abril de 2017.

Editores adjuntos nacionais / Associate Editors / Editores Asociados

Fagno da Silva Soares, Instituto Federal de Educação, Ciência e Tecnologia do Maranhão (IFMA), Núcleo de Estudos em História Oral (NEHO/USP) e líder do CLIO \& MNEMÓSINE - Centro de Estudos e Pesquisas em História Oral e Memória (IFMA), Brasil. 


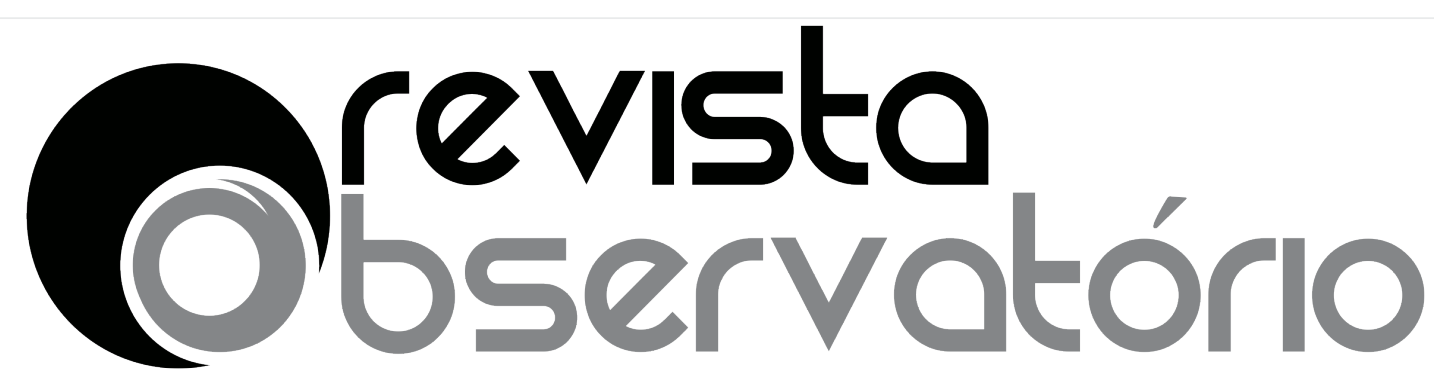

ISSN n² 2447-4266

Vol. 3, n. 2, Abril-Junho. 2017

DOI: http://dx.doi.org/10.20873/uft.2447-4266.2017v3n2p25

Marta Gouveia de Oliveira Rovai, Universidade Federal de Alfenas (UNIFAL/MG), Núcleo de Estudos em História Oral (NEHO/USP), Grupo de Pesquisa História do Brasil: memória, cultura e patrimônio

(UNIFAL/MG) e Laboratório de História Oral e Imagem (LABHOI/UFF), Brasil

Editor Geral / Chief Editor / Editor general Francisco Gilson Rebouças Porto Junior, Universidade Federal do Tocantins (UFT), Brasil.

\section{Referências}

ALMEIDA, J. R.; CALDAS, R. R. HISTÓRIA PÚBLICA E EDUCAÇÃO DEMOCRÁTICA: "Professores contra o projeto Escola Sem Partido" - Narrativas em Debate. Revista Observatório , v. 3, n. 2, p. 66-91, 1 abr. 2017.

ALMEIDA, V. DE; LOPES, C. G.; GOMES, D. R. O ENSINO DE HISTÓRIA E UM TEXTO EM CONTEXTOS: uma leitura sobre o livro "História da Liberdade no Brasil" de Viriato Corrêa. Revista Observatório , v. 3, n. 2, p. 309-336, 1 abr. 2017.

BEZERRA, C. P. A.; ALEXANDRE, J. F.; QUEIROZ, P. R. C. DE. A PRÁTICA EXTENSIONISTA E EDUCAÇÃO PATRIMONIAL: esforços em prol de uma história pública. Revista Observatório , v. 3, n. 2, p. 337-364, 1 abr. 2017.

BEZERRA, V. P.; SALES, T. B. DITADURA CIVIL MILITAR NO BRASIL E O ENSINO DE HISTÓRIA: leituras variadas e diferentes maneiras de expressão. Revista Observatório , v. 3, n. 2, p. 241-264, 1 abr. 2017.

BRANDÃO, A. H. B. A HISTÓRIA PÚBLICA E A CONSTRUÇÃO DO "POPULAR" NO ACERVO DE CORDÉIS DA FUNDAÇÃO CASA DE RUI BARBOSA (1961-2012). Revista Observatório, v. 3, n. 2, p. 197-218, 1 abr. 2017.

FARIAS, J. A. DE. EXPERIÊNCIAS DOS MILITANTES DE ESQUERDA ARMADA NOS CÁRCERES CEARENSES (1971-79). Revista Observatório , v. 3, n. 2, p. 454-479, 1 abr. 2017.

FERREIRA, R. DE A. HISTÓRIA PÚBLICA E ENSINO DE HISTÓRIA: um olhar sobre o filme no livro didático. Revista Observatório, v. 3, n. 2, p. 136-171, 1 abr. 2017.

FONSECA, V. A. DA. HISTÓRIA ESCOLAR, CINEMA BRASILEIRO E HISTÓRIA PÚBLICA: caminhos de uma memória. Revista Observatório , v. 3, n. 2, p. 92-112, 8 abr. 2017.

FRAZÃO, S. M. HISTÓRIA PÚBLICA NO BRASIL: entre interdisciplinaridade e singularidades dos saberes. Revista Observatório , v. 3, n. 2, p. 631-638, 1 abr. 2017. 


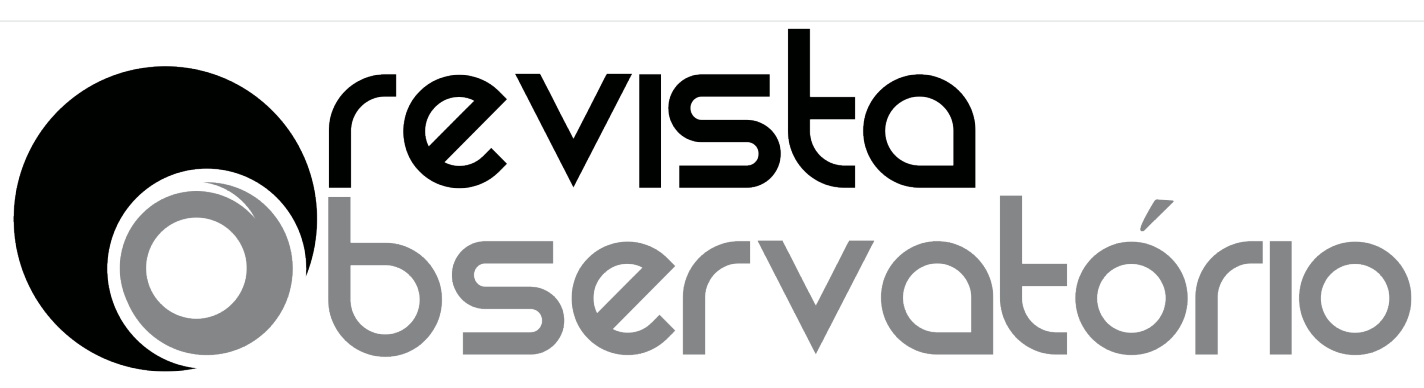

ISSN n² 2447-4266

Vol. 3, n. 2, Abril-Junho. 2017

DOI: http://dx.doi.org/10.20873/uft.2447-4266.2017v3n2p25

MENDONÇA, J. M. N.; RAMOS, R. W. AFRO-BRASILEIROS NO MUSEU PARANAENSE: silêncios, demandas públicas e ressignificações. Revista Observatório , v. 3, n. 2, p. 113-135, 1 abr. 2017.

MORAES, H. DE M.; MARREIRO, C. G.; BARRETO FILHO, E. T. La A PUBLICIDADE NA TELEVISÃO E A OBESIDADE INFANTIL: Características e revisão de literatura no contexto brasileiro. Revista Observatório , v. 3, n. 2, p. 503-523, 1 abr. 2017.

MUYLAERT MAGER, J.; MAUAD, A. M. EM CARTAZ: festivais de cinema de arquivo - preservação e público. Revista Observatório, v. 3, n. 2, p. 283-308, 1 abr. 2017.

PINHO, M. DE F. DE M.; SILVA, S. M. DE M. NO SILÊNCIO OBSEQUIOSO, PREPARO MINHA PRÓPRIA DEFESA PADRE CÍCERO: arquivista de si mesmo. Revista Observatório, v. 3, n. 2, p. 172-196, 1 abr. 2017.

RODRIGUES, W.; MESQUITA, T. R.; COELHO, E. S.; CANÇADO, A. A UTILIZAÇÃO DO PLANEJAMENTO ESTRATÉGICO SITUACIONAL NA GESTÃO DA PRÓ-REITORIA DE EXTENSÃO E CULTURA (PROEX) DA UNIVERSIDADE FEDERAL DO TOCANTINS (UFT). Revista Observatório, v. 3, n. 2, p. 548-568, 1 abr. 2017.

RODRÍGUEZ, V. M. A. PINTURA Y EDUCACIÓN O EDUCACIÓN Y PINTURA. Una propuesta desde la didáctica. Revista Observatório , v. 3, n. 2, p. 480-502, 1 abr. 2017.

ROVAI, M. G. DE O. HISTÓRIA PÚBLICA: a comunicação e a educação histórica. Revista Observatório , v. 3, n. 2, p. 41-65, 1 abr. 2017.

SANTA CRUZ, L. 50 ANOS DE JORNALISMO DA GLOBO: recordar para reafirma. Revista Observatório , v. 3, n. 2, p. 365-391, 1 abr. 2017.

SILVA, F. B. SOBRE AS PERGUNTAS QUE PODEMOS FAZER AOS ARQUIVOS VISUAIS: por uma história pública, comunicação e ensino. Revista Observatório , v. 3, n. 2, p. 219-240, 1 abr. 2017.

SILVA, S. P. DA. PENSANDO A ESCRITA DE SI COMO FONTE DE CONHECIMENTO HISTÓRICO. Revista Observatório , v. 3, n. 2, p. 265-282, 1 abr. 2017.

SOARES, F. DA S. A HISTÓRIA PÚBLICA NO BRASIL ENTRE PRÁTICAS E REFLEXÕES: a oficina historiográfica de Ricardo Santhiago entre a história oral e a história pública. Revista Observatório, $\mathrm{V}$. 3, n. 2, p. 569-585 (PT) 586, 1 abr. 2017.

SOUSA, F. DAS C.; VACOVSKI, E.; SOARES, F. DA S. PIQUIÁ DA CONQUISTA: a vitória dos de baixo contra os gigantes de ferro. Revista Observatório , v. 3, n. 2, p. 417-453, 1 abr. 2017.

TESKE, W.; ERTZOGUE, M. H. IDENTIDADE CULTURAL E INCLUSÃO TECNOLÓGICA EM UMA PERSPECTIVA FOLKCOMUNICACIONAL DA COMUNIDADE QUILOMBOLA LAGOA DA PEDRA, ARRAIAS-TO. Revista Observatório , v. 3, n. 2, p. 524-547, 1 abr. 2017.

ULISSES, I. B. ARGUMENTOS POR UMA HISTÓRIA PÚBLICA: perspectivas e possibilidades. Revista Observatório , v. 3, n. 2, p. 622-630, 1 abr. 2017.

VICENTE, M. F. "E OS CABOCLOS FORAM SE ACABANDO": A (re)construção de sentidos do passado dos Caboclos da Vila de Guarany. Revista Observatório , v. 3, n. 2, p. 392-416, 1 abr. 2017. 